\title{
Características de la estructura corporal, hábitos dietéticos y función renal a través de la vida, de personas saludables de clase media entre los 20 y 80 años de edad de Lima
}

Body features, dietary habits and renal function of healthy middle class people between 20 and 80 years of age in Lima

\author{
Ana Rosa Vilela Sangay 1,c, Javier Antonio Cieza Zevallos ${ }^{1, a ; ~ 2, b}$
}

\section{RESUMEN}

Objetivos: Describir los cambios en el agua corporal, masa magra, contenido de grasa, aclaramiento de creatinina y urea y características dietéticas de personas saludables en Lima-Perú. Material y métodos: Se incluyeron personas de sexo y edades entre 20 y 80 años, comparables con Índice Masa Corporal normal, autosuficientes, calidad de vida satisfactoria y sin enfermedad crónica. Se midieron los datos estructurales con Bioimpedancia. La función renal se determinó mediante la creatinina y urea en sangre y el aclaramiento de creatinina y de urea. Las características dietéticas se infirieron de la medición de urea, sodio y potasio en la misma muestra de orina. Resultados: Hubo diferencia significativa en: agua corporal, grasa, masa magra, creatinina (sérica y urinaria) y urea sérica entre sexos. La masa magra se relacionó directamente con el agua corporal $(r=0,81 ; p=0,000$ en hombres y $r=0,465 ; p=0,000$ en mujeres) e inversamente con la grasa. En el análisis de regresión lineal multivariado, únicamente la masa magra, grasa y agua corporal mostraron significancia estadística con la edad, pero los cambios de estas variables difirieron entre hombres y mujeres. La creatinina y urea sérica no cambiaron con la edad, pero sí el aclaramiento de ambas. El aclaramiento de urea tuvo regresión lineal en hombres y cúbica en las mujeres. Hubo correlación negativa entre edad e ingesta proteica en hombres $(\mathrm{r}=-0,594 ; \mathrm{p}=0,006)$, sal sódica $(\mathrm{r}=-0,451 ; \mathrm{p}=0,021)$ y potasio $(\mathrm{r}=-0,443$; $\mathrm{p}=0,023)$ en mujeres. Conclusiones: La estructura corporal, filtración glomerular y hábitos dietéticos cambian con la edad en nuestra población normal, pero con características diferentes entre hombres y mujeres.

PALABRAS CLAVE: Somatotipos, conducta alimentaria, pruebas de función renal, sodio, potasio, creatinina, urea. (Fuente: DeCS BIREME).

\section{SUMMARY}

Objectives: To describe changes in body water, lean body mass, fatty content, creatinine and urea clearance and dietary habits of healthy persons in Lima. Methods: Persons of both sexes between 20 and 80 years with normal body mass index, self-sufficient, with satisfactory quality of life and without chronic renal disease were included in the study. Electric bio impedance was used to get body structural data. Renal function was measured with creatinine clearance, serum creatinine and urea. Dietary features were inferred from urea, sodium and potassium

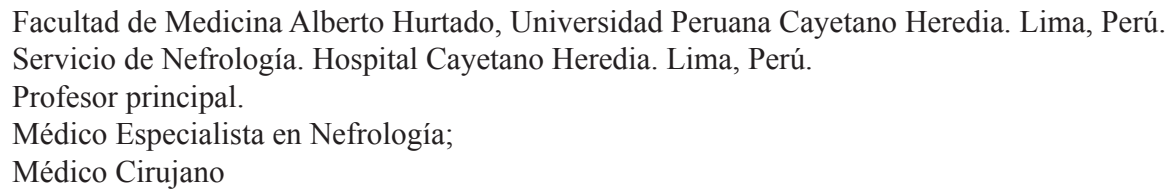


measurements from a urine sample. Results: A statistical significant difference in sexes was found for body water, fatty content, lean body mass, creatinine (in serum and urine) and urea. Lean body mass was directly correlated with body water ( $\mathrm{r}=0.81 ; \mathrm{p}=0.000$ in males and $\mathrm{r}=0.465 ; \mathrm{p}=0.000$ in females) and inversely correlated with fatty content. The multivariate lineal regression analysis only found correlation of lean body mass, fatty content and body water with age, but changes in these variables differed between males and females. Serum urea and creatinine did not change with age, but the clearance of both of them did it. Urea clearance showed linear correlation in males but cubic in females. A negative correlation between age and protein intake was observed ( $\mathrm{r}=-0.594 ; \mathrm{p}=0.006)$, sodium salt $(\mathrm{r}=-0.451 ; \mathrm{p}=0.021)$ and with potassium in females. Conclusions: Body structure, glomerular filtration and dietary habits change with age in our healthy population but with differences by sex.

KEYWORDS: Somatotypes, feeding behavior, kidney function tests, sodium, potassium, creatinine, urea. (Source: MeSH NLM).

\section{INTRODUCCIÓN}

Nuestra vida es un proceso dinámico en tres aspectos fundamentales: en la estructura material que compone nuestro cuerpo, en el proceso dinámico que lo anima y en el proceso comprensivo de nuestra existencia que es el espíritu. Estos tres procesos funcionan íntimamente relacionados entre sí y en formas dinámicas muy peculiares. El proceso de maduración biológico de nuestro cuerpo requiere cuidado y afecto, que se inicia en la vida intrauterina y el primer año de vida extrauterina. Este proceso es principalmente brindado por la madre y luego por la familia. El alma que interactúa y moldea el cuerpo hasta su plena madurez, incuba y desarrolla el espíritu humano, entendido éste como aquella situación que sobrepasa lo natural y permite desarrollar nuestra autorreflexión, creatividad y trascendencia a nuestra vida corporal. Gracias a esto, se construye el intelecto que gobierna nuestras emociones, miedos y pasiones.

Concebida de esta manera, la salud es el proceso que conlleva nuestra existencia en forma armónica con nuestro medio ambiente y al cual acertadamente la Organización Mundial de la Salud (OMS) la concibe como aquel estado de completo bienestar físico, mental y social, y no solamente la ausencia de afecciones o enfermedades (1). Una expresión de la salud es la presencia de una estructura corporal armónica de su masa biológica útil para las diversas funciones vitales (la masa magra); por ejemplo, el movimiento, la defensa ante injurias externas propias de la vida diaria, la realización de actividades idóneas para obtener nuestros alimentos y el mantenimiento del ambiente interno o "medio interno". Este medio, concebido por el gran fisiólogo francés Claude Bernard, permite una comunicación idónea y relativamente estable entre nuestras células, tejidos, órganos y sistemas para funcionar como una unidad vital integrada, capaz de cambiar según se requiera (reostasis) hacia sistemas constantemente armónicos con el ambiente que nos rodea (2).

Por tanto, es importante conocer cómo cambia la estructura del cuerpo humano en personas que viven saludablemente en nuestra sociedad, sabiendo que hay datos provenientes de otras poblaciones que podrían no ser del todo semejantes a la nuestra (3-5). Esta reflexión se sustenta en el saber que el ser humano según el ambiente donde vive, interactúa con el entorno que lo rodea, se nutre de los alimentos propios de estos ámbitos y a las costumbres adquiridas históricamente (6).

El objetivo de este estudio fue describir los cambios en el agua corporal, la masa magra y el contenido de grasa corporal en personas de ambos sexos consideradas saludables, de entre veinte y ochenta años, cuya estructura corporal era aceptada como "normal", (Índice de Masa Corporal (IMC) entre 20 y $24 \mathrm{~kg} / \mathrm{m}^{2}$ ). Además, eran personas que tenían una interacción armónica con su medio ambiente en función de los quehaceres propios de su edad, no padecían de enfermedades crónicas conocidas (hipertensión arterial, diabetes mellitus), no consumían fármacos, eran autosuficientes y aceptaban desconocer tener enfermedad alguna manifiesta o detectada, sintiéndose satisfechos con su vida actual. El objetivo secundario fue describir sus hábitos alimentarios como el consumo de sal, potasio y proteínas y la evolución de la función renal medida como aclaramiento de creatinina.

En nuestra opinión, la relevancia de este estudio radica en reconocer si nuestro concepto de estructura corporal se ciñe a lo reportado en otras observaciones, desde la madurez biológica hacia los veinte años hasta la senectud alrededor de los ochenta. Asimismo, explorar si nuestros hábitos dietéticos son los recomendados 
para mantener una estructura corporal saludable, y finalmente evaluar si la función renal, reguladora del medio interno, se mantiene adecuadamente funcional sobre todo en edades avanzadas.

\section{MATERIAL Y MÉTODOS}

Estudio descriptivo y transversal, realizado en mujeres y varones de edades entre los 20 y 82 años. Los criterios de inclusión fueron: IMC entre 20 y 25 $\mathrm{kg} / \mathrm{m}^{2}$ como valor mínimo y máximo, tener una vida normal activa, autosuficientes; que no tengan diabetes mellitus, hipertensión arterial ni otra enfermedad crónica de cualquier causa y que no tomaban medicamentos; se alimenten en forma rutinaria según sus costumbres y estar satisfechos con su vida actual, expresado explícitamente, y aceptación de participar voluntariamente en el estudio.

Los participantes fueron seleccionados entre médicos, estudiantes de medicina, sus familiares y también familiares de pacientes de un hospital general del Ministerio de Salud.

A cada participante se le determinó peso, talla y se colectó orina de 24 horas en un día rutinario, según la decisión de cada participante para no interferir con su vida diaria. Al día siguiente se les tomó una muestra de sangre matutina y se determinó urea, creatinina y electrolitos en sangre y orina de 24 horas. Con estos datos se calculó el IMC, la excreción diaria de urea y creatinina normalizada a su peso, el aclaramiento de urea y creatinina normalizado a una superficie corporal de 1,73 $\mathrm{m}^{2}$ y se extrapoló el consumo de sal, proteínas y potasio diario, según el peso de cada persona. El agua corporal, la masa magra y la grasa se determinó con una balanza de bioimpedancia eléctrica.

Los datos fueron almacenados en una base de datos electrónica y fueron informados a cada persona participante para su consideración personal. Posteriormente, se procedió al análisis de los datos con el programa SPSS v 18.

El trabajo contó con la autorización del Comité de Ética del Hospital Cayetano Heredia de Lima Perú.

\section{RESULTADOS}

Participaron 23 varones y 30 mujeres cuyas características generales y de su función renal se presentan en la tabla 1.

El análisis de regresión lineal multivariado en función de la edad, solamente mostraron asociación significativa, la masa magra, la grasa y el agua corporal (Gráficos 1,2 y 3).

Los datos de las costumbres dietéticas rutinarias de ingesta de proteínas, sal sódica y potasio, inferido de las excreciones de urea, sodio y potasio urinario en función del sexo se presentan en la tabla 2.

Tabla 1. Datos generales de los participantes según sexo.

\begin{tabular}{|c|c|c|c|c|}
\hline \multirow{2}{*}{ Variable } & Varones & Mujeres & Total & \multirow{2}{*}{$\mathbf{p}$} \\
\hline & Media \pm DS & Media \pm DS & Media \pm DS & \\
\hline Edad (años) & $43,7 \pm 22,88$ & $41,77 \pm 20,74$ & $40,41 \pm 20,65$ & 0,750 \\
\hline $\operatorname{IMC}\left(\mathrm{Kg} / \mathrm{m}^{2}\right)$ & $23,87 \pm 2,01$ & $23,41 \pm 1,93$ & $23,65 \pm 1,98$ & 0,400 \\
\hline Agua Corporal (\%) & $54,92 \pm 5,2$ & $49,53 \pm 4,42$ & & 0,000 \\
\hline Masa Magra (\%) & $40,06 \pm 5,77$ & $34,28 \pm 5,06$ & & 0,000 \\
\hline Grasa $(\%)$ & $25,83 \pm 8,72$ & $31,25 \pm 5,57$ & & 0,008 \\
\hline Creatinina sérica (mg/dl) & $0,88 \pm 0,15$ & $0,63 \pm 0,08$ & & 0,000 \\
\hline Flujo Urinario (ml/min) & $1,23 \pm 0,61$ & $1,32 \pm 0,61$ & & 0,619 \\
\hline Creatina urinaria $(\mathrm{mg} / \mathrm{kg} / \mathrm{d})$ & $22,68 \pm 7,72$ & $18,16 \pm 5,31$ & & 0,023 \\
\hline $\begin{array}{l}\text { Aclaramiento de creatinina }(\mathrm{ml} / \\
\mathrm{min} / 1,73 \mathrm{~m} 2 \mathrm{SC})\end{array}$ & $120,62 \pm 45,03$ & $128,48 \pm 38,83$ & & 0,529 \\
\hline Urea sérica $(\mathrm{mg} / \mathrm{dl})$ & $29,52 \pm 8,07$ & $24,07 \pm 8,26$ & & 0,030 \\
\hline Aclaramiento de urea $\left(\mathrm{ml} / \mathrm{min} / 1,73 \mathrm{~m}^{2} \mathrm{SC}\right)$ & $56,33 \pm 30,13$ & $59,68 \pm 22,50$ & & 0,668 \\
\hline Relación Urea/Creatinina sérica & $33,66 \pm 8,30$ & $38,26 \pm 11,21$ & & 0,132 \\
\hline
\end{tabular}

IMC: Índice de masa corporal 
Tabla 2. Características de la ingesta diaria rutinaria de proteínas, sal sódica y potasio (media \pm DS).

\begin{tabular}{lcccc}
\hline \multirow{2}{*}{ Característica } & Varones & Mujeres & Total & \multirow{2}{*}{$\mathbf{p}$} \\
\cline { 2 - 4 } & $\mathbf{( n = 2 0 )}$ & $\mathbf{( n = 2 6 )}$ & $\mathbf{( n = 4 6 )}$ & \\
\hline Excreción de Sodio (g/día) & $4,24 \pm 1,84$ & $3,62 \pm 1,35$ & $3,92 \pm 1,62$ & 0,111 \\
Excreción de Potasio (g/día) & $2,39 \pm 1,21$ & $2,21 \pm 1,5$ & $2,3 \pm 1,36$ & 0,802 \\
Excreción de Creatinina (g/día) & $1,66 \pm 0,48$ & $1,07 \pm 0,31$ & $1,35 \pm 0,49$ & 0,023 \\
Ingesta Diaria Proteínas (g/kg/día) & $1,94 \pm 0,48$ & $0,87 \pm 0,25$ & $0,9 \pm 0,38$ & 0,341 \\
\hline
\end{tabular}

Hombres

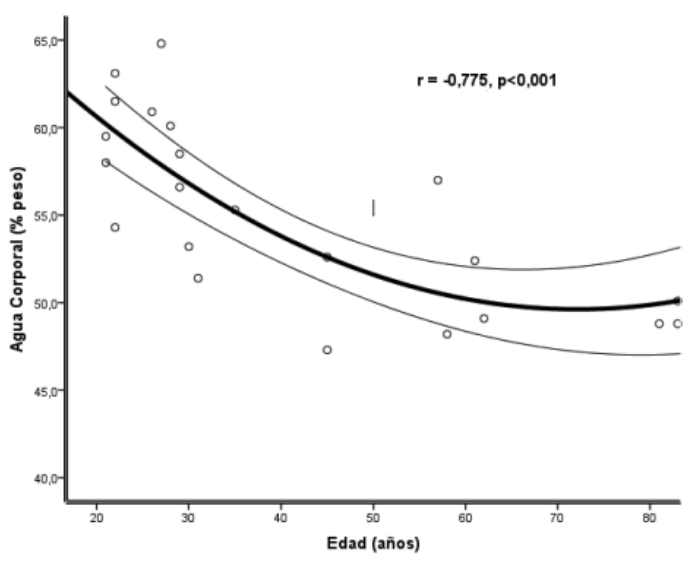

Mujeres

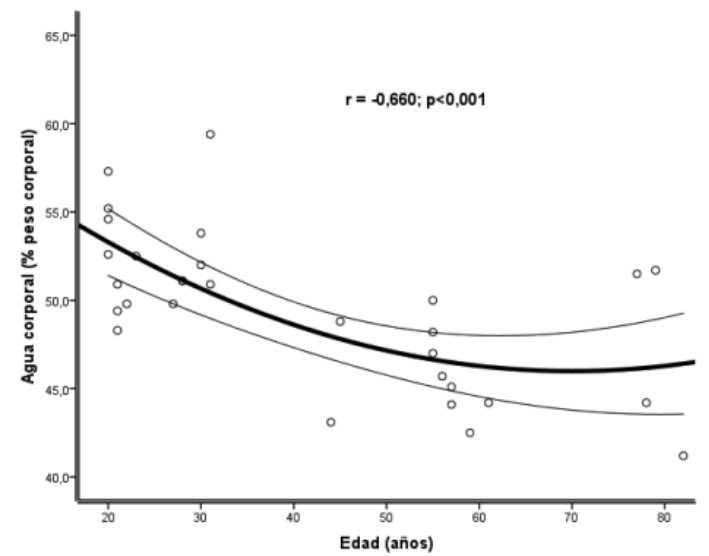

Gráfico 1. Evolución del agua corporal del ser humano adulto sano. Lima-Perú.

Hombres

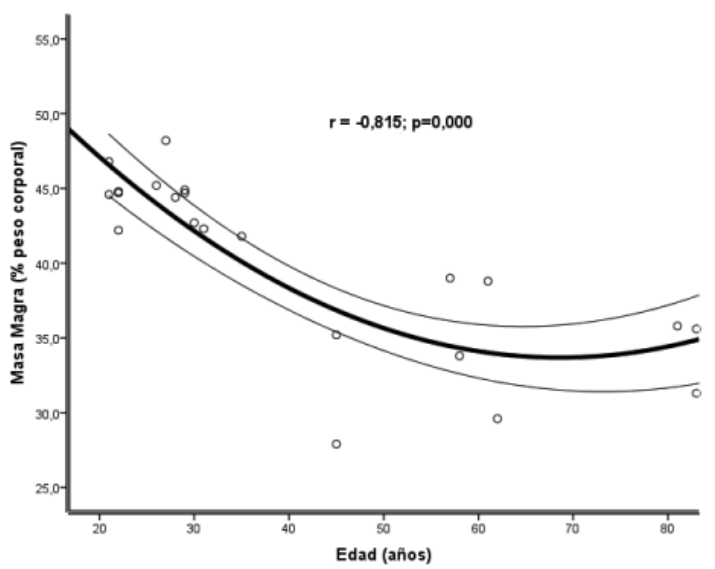

Mujeres

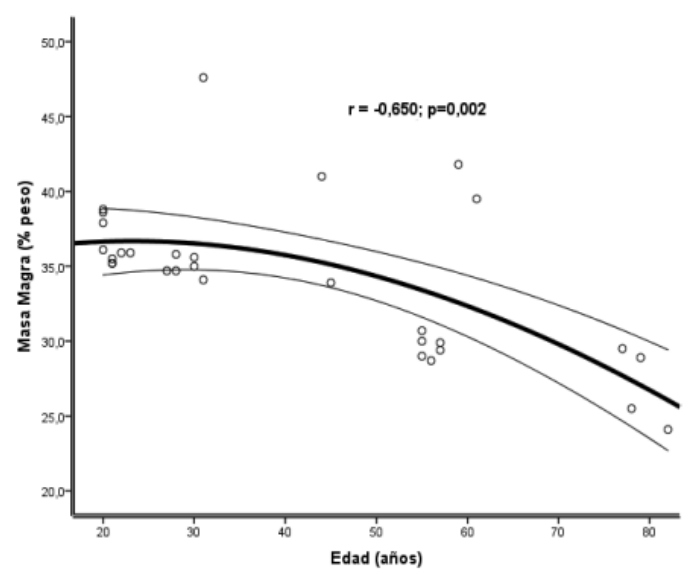

Gráfico 2. Evolución de la masa magra corporal del ser humano adulto sano. Lima-Perú.

Sólo la ingesta dietética proteica diaria ajustada al peso de la persona en los varones (IDP) mostró una correlación significativa negativa con la edad $(\mathrm{r}=-0,594, \mathrm{p}=0,006)$. En las mujeres la IDP no mostró correlación con la edad, pero sí mostraron una correlación negativa con la edad, la ingesta de sal sódica $(\mathrm{r}=-0,451, \mathrm{p}=0,021)$ y la ingesta de potasio $(\mathrm{r}=-0,443, \mathrm{p}=0,023)$.
Ni la creatinina, ni la urea sérica mostraron cambios en sus valores durante la vida. La función renal vista como aclaramiento de creatinina y de urea a través de la vida se muestran en los gráficos 4 y 5 .

El análisis de regresión lineal multivariada entre la masa magra y las diversas variables antropométricas y de función renal estudiadas, solamente mostró relación 


\section{Hombres}

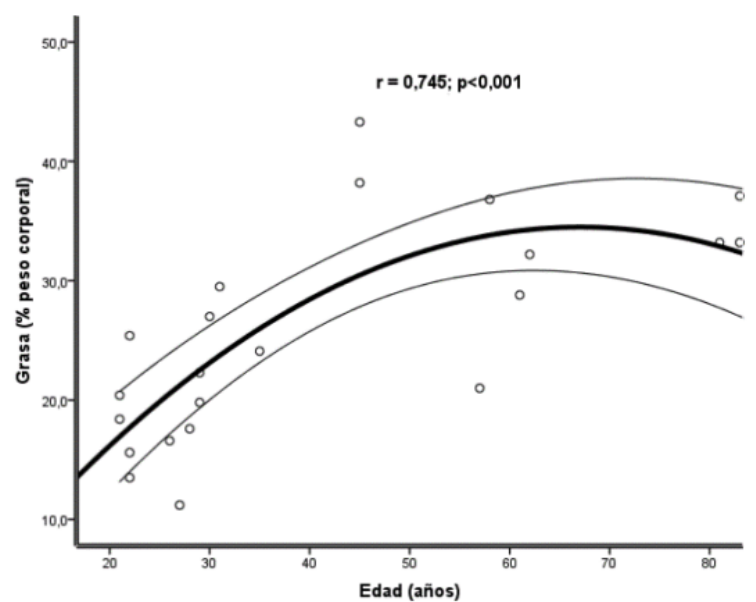

Mujeres

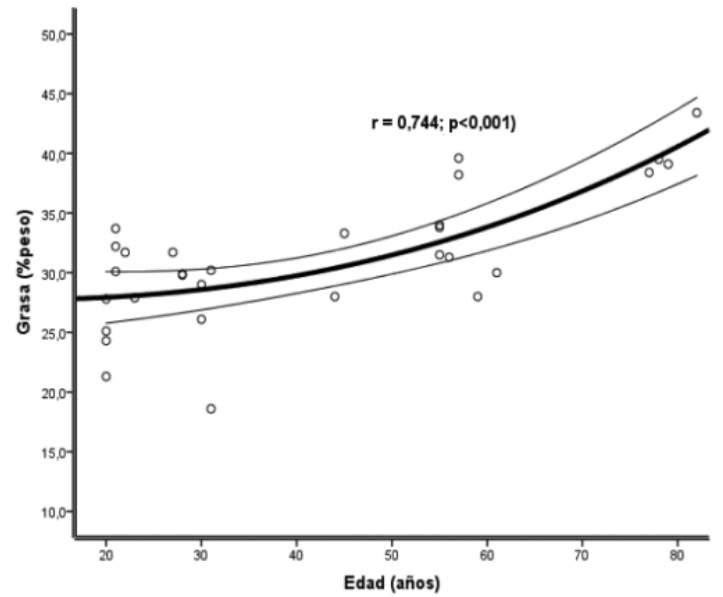

Gráfico 3. Evolución de la grasa corporal del ser humano adulto sano. Lima-Perú.
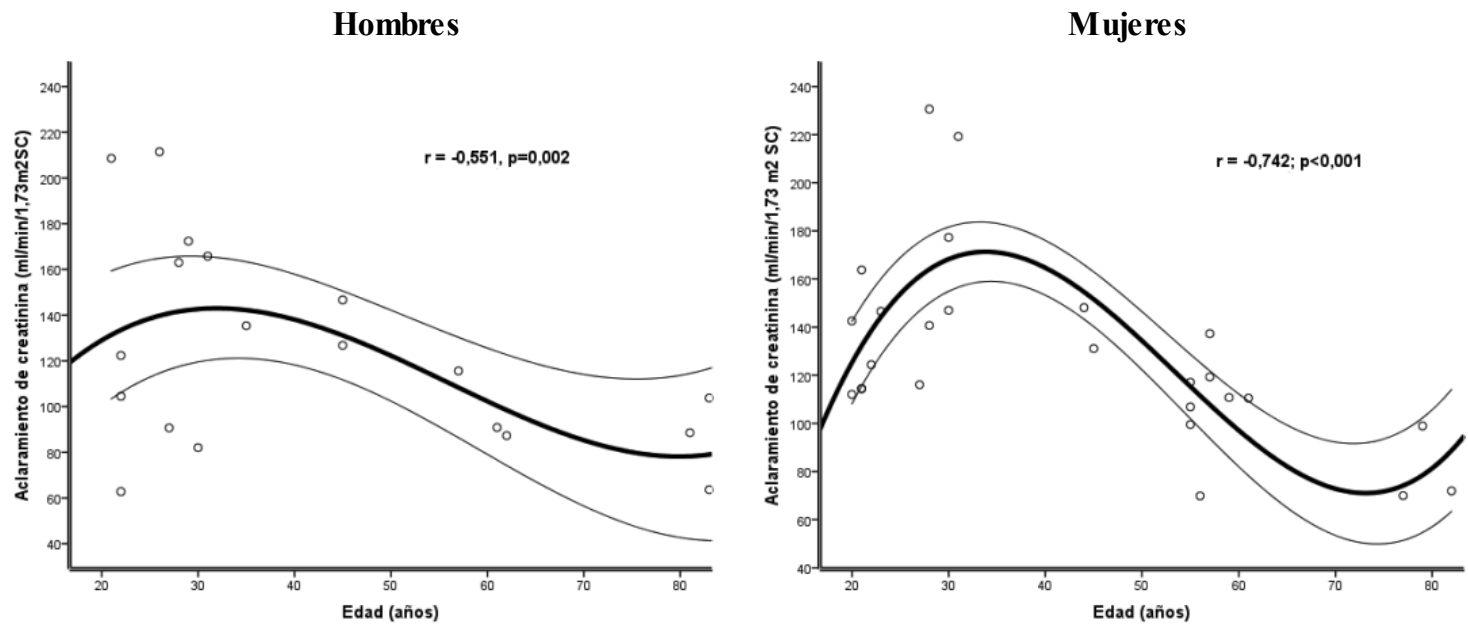

Gráfico 4. Evolución del aclaramiento renal de creatinina en el adulto sano según la edad. Lima-Perú.

Hombres

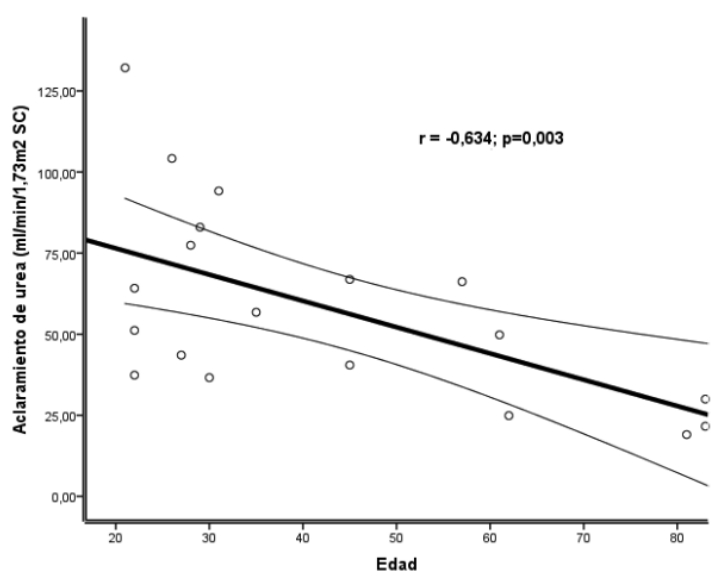

Mujeres

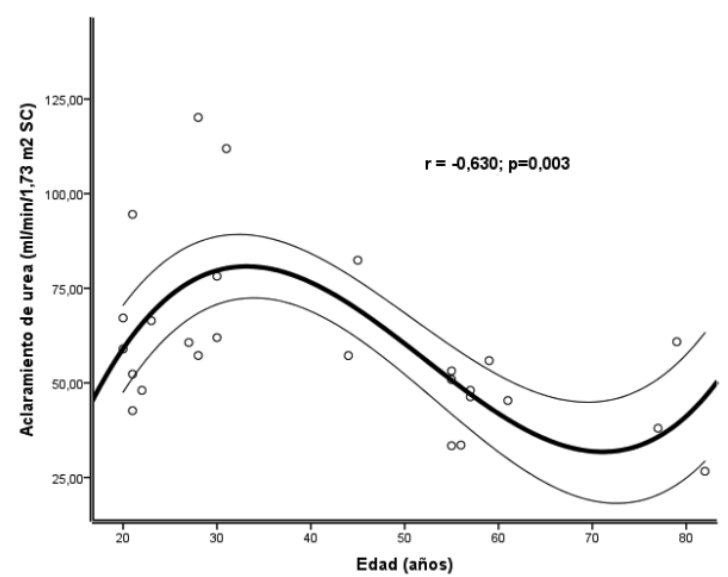

Gráfico 5. Evolución del aclaramiento renal de urea en el adulto sano según la edad. Lima-Perú. 

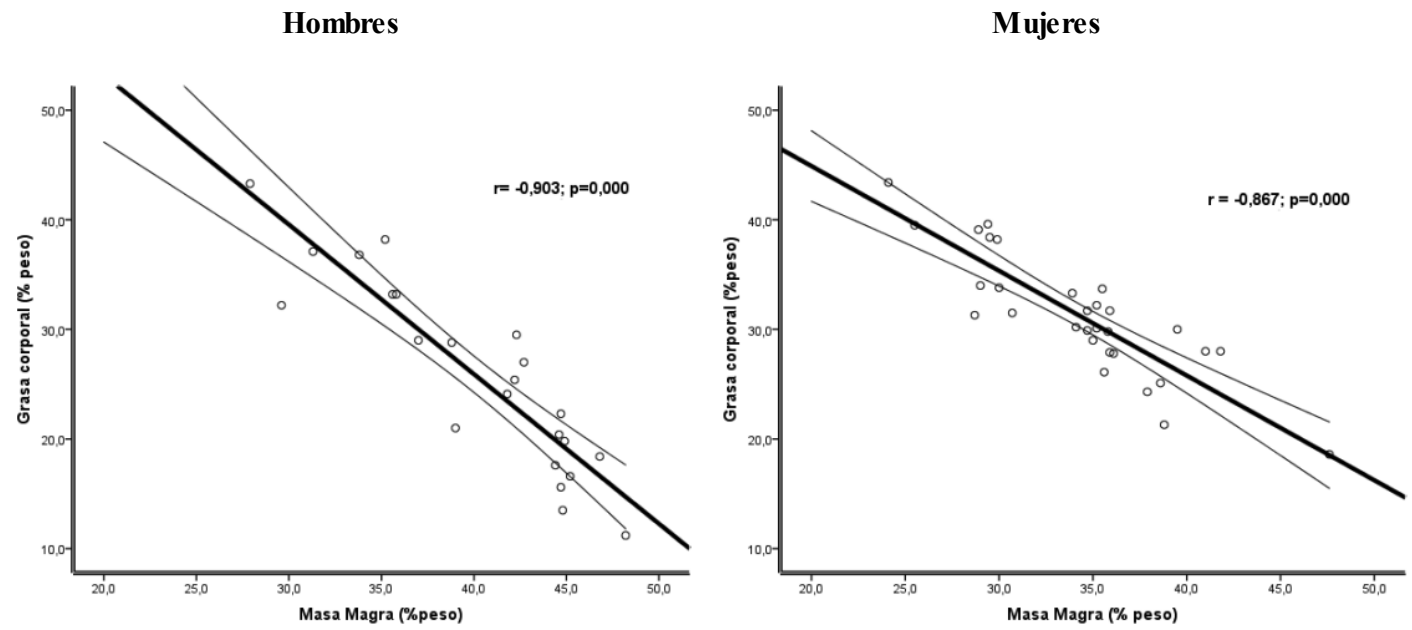

Gráfico 6. Correlación en la masa magra y la grasa corporal en sujetos sanos. Lima-Perú.
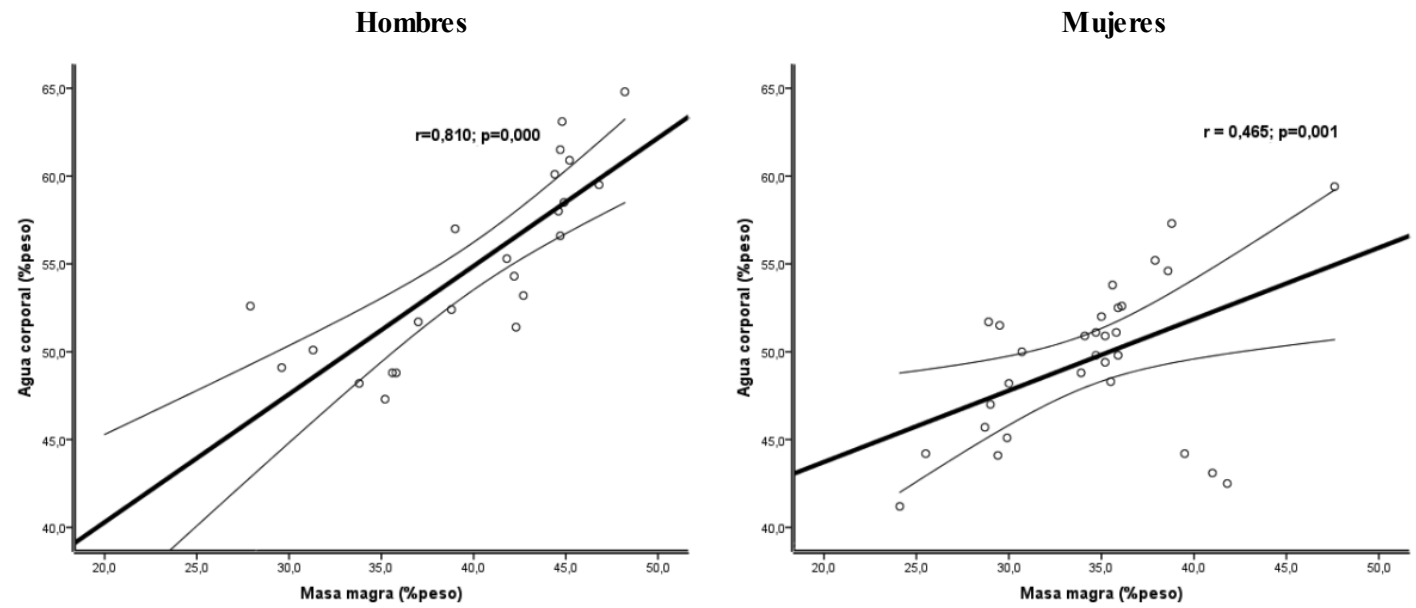

Gráfico 7. Correlación en la masa magra y el agua corporal en sujetos sanos. Lima-Perú.

significativa con la grasa y con al agua corporal (Gráficos 6 y 7).

\section{DISCUSIÓN}

Aceptando que la muestra del presente trabajo es limitada en número, subrayamos dos aspectos: el primero, relativo a la exigencia de los criterios de inclusión y consideraciones sobre la persona normal, y el segundo en la dificultad operativa para desarrollar el proceso metodológico de evaluación, que incluía la necesidad de cumplir con recolectar orina de 24 horas y a la mañana siguiente, tener disponibilidad para el muestreo de sangre correspondiente, tomando en cuenta que prácticamente todos los participantes eran personas en actividad diaria productiva. La gran mayoría de trabajos relativos a este tema consultados en la literatura, incluyen poblaciones en general que no necesariamente siguen los criterios de normalidad aquí considerados; esto es, exclusión de personas con sobrepeso, diabéticos o hipertensos no detectados, personas con enfermedad renal crónica (ERC) en estadios tempranos que suelen ser asintomáticos, y que ahora sabemos pueden ser altamente prevalentes en la sociedad $(7,8)$. Por esta razón, publicaciones científicas con las características de esta muestra son escasas o inexistentes en nuestra región y en el Perú. También debemos recordar que luego de los cuarentaicinco o cincuenta años de vida, la probabilidad de carecer de alguna dolencia crónica sentida es escasa.

Nuestros resultados muestran que al transcurrir la vida luego de haber alcanzado la madurez biológica, hay una reingeniería permanente de nuestra estructura corporal que nos permite tener una vida satisfactoria y armónica con nuestro entorno, y ser independientes 
aún a edades como los ochenta años. Esta reingeniería no sigue modelos lineales como lo muestran los gráficos 1,2 y 3 , sino relaciones cuadráticas, que induce a pensar que estos cambios tienen un límite, más allá de los cuales la salud está perdida, y que esta reingeniería en personas sanas de clase media, difiere entre los hombres y las mujeres.

Distorsiones de la estructura corporal por diversas situaciones, ocurridas tempranamente pueden permitir retornar a parámetros normales con mayor probabilidad que si estos ocurren tardíamente. Este es un problema ligado al concepto de salud del ciudadano. Un trabajo nacional relativo al tema, realizado en personas ambulatorias del como norte de Lima, encontró una prevalencia de sobrepeso del $46,3 \%$ y obesidad del $18,1 \%$ asociados a un bajo nivel de educación, y alerta de la magnitud del problema en nuestra sociedad (9).

Otro aspecto importante es reconocer que la disminución de la masa magra en la persona sana está íntimamente relacionada con el aumento de la grasa corporal y directamente relacionada con la disminución del agua corporal en el transcurrir de la vida. Esto es, la preservación de las formas antropométricas es una situación relevante que permite intuir estar en el camino de un ser humano saludable y corregir oportunamente las distorsiones cuando esta percepción se altera. Esta situación se refleja en el modelo de cambios observados al trascurrir la vida, y difiere entre hombres y mujeres en lo relativo a la masa magra y grasa corporal, no así en el agua.

Al observar los cambios de la masa magra de los varones, es fácil apreciar que estos cambios "tienen un límite" hacia los cincuenta o sesenta años, valor que es mantenido en las mujeres hasta aproximadamente la misma edad y encima de la cual en éstas se observa una caída notable. Esta relación ocurre en forma muy parecida pero inversa para el contenido de grasa corporal, resaltando que la grasa corporal en las mujeres parece empezar a elevarse desde los cuarenta años y se torna notoria luego de los sesenta, situación que probablemente esté relacionada a nuestra cultura. Es decir, el varón es más proclive, por el trabajo u otras razones, a mantener una masa magra más estable dentro de la misma forma antropométrica que la mujer, quien para hacerlo requiere incrementar su contenido graso bajo diversos mecanismos como la disminución de la actividad física o el tipo de alimentación.

Al respecto, queremos acotar que la evolución de nuestro cuerpo es el resultado de un conjunto de situaciones: 1) formas ancestrales aprendidas desde la infancia, 2) historia y costumbre alimentaria adquiridas a través del tiempo, 3) conceptos de actividad física y laboral ligada al sexo y aceptada socialmente y 4) construcción del concepto de la propia salud, que requiere educación y reflexión constante de la propia existencia. Esto explicaría el hallazgo de Cieza y Rosas (9), relativo a las diferencias que observamos en nuestra propia sociedad desde la infancia hasta la adultez y entre diversas sociedades actuales e históricas. Nuestra estructura corporal no depende pues únicamente de una o dos variables, es altamente compleja y debemos así entenderla.

Es interesante observar que, llegada la adultez, hacia los veinte años, tanto hombres y mujeres guardan en gran medida, contenidos de agua esperables para cualquier humano (60\% hombres y 50\% mujeres). Los primeros también lo hacen para el contenido de masas magra y grasa, no así las mujeres, que, admitiendo la posibilidad de sesgo del tamaño de la muestra, parece mostrar tempranamente una masa magra límite inferior y posteriormente un crecimiento significativo del contenido graso.

Un segundo tema a considerar es el relativo a la evolución de la función renal a través de la vida adulta. Tanto hombres como mujeres mostraron un incremento del aclaramiento de la creatinina hacia los treinta años que luego tuvo curso decreciente hasta edades muy avanzadas como los ochenta años, pero manteniendo constante el valor de la creatinina sérica. Hay dos aspectos a resaltar, el primero relacionado al incremento de la filtración glomerular hacia los treinta años (hiperfiltración), que parece jugar un rol importante en la pendiente de caída de la tasa de filtración glomerular en las mujeres, cuya explicación probable tocaremos luego, y el segundo relacionado a los valores del aclaramiento de creatinina, que aún hasta los ochenta años, no cae debajo de los $60 \mathrm{ml} /$ $\mathrm{min} / 1,73 \mathrm{~m}^{2} \mathrm{SC}$ tanto en varones cuanto en mujeres. Considerando que el concepto de "insuficiencia renal" implica una disminución del aclaramiento de la creatinina por debajo de los $60 \mathrm{ml} / \mathrm{min} / 1,73 \mathrm{~m}^{2} \mathrm{SC}$, la vida saludable no implica insuficiencia renal aún para edades avanzadas.

Otra observación de los resultados muestra que, si bien el aclaramiento de creatinina sigue modelos cualitativamente similares en hombres y mujeres, el aclaramiento de urea no lo hace. En los varones el aclaramiento de la urea sigue una relación lineal decreciente relacionada a la edad, mientras en 
las mujeres sigue un modelo de regresión cúbica. Aceptando que la urea traduce el catabolismo proteico y en una persona sana este se relaciona directamente con su ingesta dietética, los resultados son coherentes con el mayor grado de hiperfiltración observado en las mujeres hacia los treinta años y también con los cambios corporales vistos en la masa magra en las mujeres que declina en forma importante luego de los cuarenta años.

La edad mostró una relación lineal decreciente con el consumo de proteínas en los varones $(\mathrm{r}=-$ $0,594 ; \mathrm{p}=0,006)$ pero no en las mujeres, situación comprensible por las características mostradas en el tipo de relación entre la edad y el aclaramiento de urea en ellas.

Se debe resaltar el elevado consumo de sodio, 4,24 $\pm 1,84 \mathrm{~g} /$ día en varones y $3,62 \pm 1,35 \mathrm{~g} /$ día en mujeres, con un promedio de 3,92 $\pm 1,62 \mathrm{~g}$ /día bastante más allá de lo recomendado por la OMS, la cual sugiere un consumo menor a $2 \mathrm{~g}$ por día (10). El consumo promedio de sodio encontrado es consistente con otros hallazgos en América Latina, así como también en estudios realizados en Perú.

Un estudio realizado en 17033 individuos entre 35-70 años de 4 países de Sudamérica (Argentina, Brasil, Chile y Colombia), encontró una excreción promedio de sodio de 4,70 $\pm 1,43 \mathrm{~g} /$ día, siendo la más alta la encontrada en Colombia $(4,89 \pm 1,48 \mathrm{~g}$ /día), seguida de Chile (4,88 $\pm 1,45 \mathrm{~g} /$ día), luego Argentina $(4,66 \pm 1,35 \mathrm{~g} /$ día $)$ y por último Brasil $(4,57 \pm 1,47$ g/día) (7). En Perú, se realizó un estudio transversal en el año 2017 en una población semiurbana al norte del país, en 409 personas con edad promedio de 45,7 años, encontrando un consumo de sodio promedio de $4,40 \pm 2,1 \mathrm{~g} /$ día. Asimismo, en un estudio hecho entre los años 2013 y 2014 en la ciudad de Lima, con 140 estudiantes universitarios, se encontró un consumo de sal promedio de $11 \mathrm{~g} /$ día que equivalen a $4,40 \mathrm{~g}$ de sodio/día (9). En nuestro estudio el consumo se torna decreciente con la edad en las mujeres $(r=-0,451$; $\mathrm{p}=0,021)$. El elevado consumo de sal en la persona sana parecería no tener mayor efecto per se, pero que sí podría tenerlo cuando existen eventos que perturban la salud en general, por ejemplo, en la obesidad, situación que debería tenerse en consideración para recomendaciones en la salud pública.

El consumo de potasio en términos generales está dentro de lo esperable para ambos sexos, al igual que el consumo de sal decrece en las mujeres significativamente $(\mathrm{r}=-0,443 ; \mathrm{p}=0,023)$ y no en los hombres. En un estudio llevado a cabo en España con 47 mujeres sanas, estudiantes universitarias, se encontró un consumo de potasio de $1526 \pm 208.5$ $\mathrm{mg} / 1000 \mathrm{kcal}$, que para una dieta de $2000 \mathrm{kcal}$ diarias está ligeramente mayor a $1 \mathrm{mEq}$ de potasio por kilogramo de peso diario (asumiendo un peso promedio de $70 \mathrm{~kg}$ ), de acuerdo a lo recomendado por la OMS (12). En un estudio en Perú mencionado previamente se encontró un consumo de potasio promedio de 2,2 $\pm 1,3 \mathrm{~g}$ /día (8). En el estudio realizado en cuatro países latinoamericanos mencionado previamente, se encontró un promedio de 2,09 $\pm 0,58 \mathrm{~g} /$ día, siendo Colombia el país con un mayor consumo $(2,33 \pm 0,60$ g/día), seguida de Brasil (2,32 $\pm 0,53 \mathrm{~g} /$ día), Chile $(2,06 \pm 0,60 \mathrm{~g} /$ día $)$ y por último Argentina $(1,74 \pm 0,40$ g/día) (7).

Estos hallazgos conducen a decir con fundamento, que los hábitos alimentarios evolucionan diferenciadamente en hombres y mujeres al transcurrir la vida y conducen a remodelaciones corporales diferenciadas entre ambos sexos, que probablemente son el reflejo de nuestra cultura.

En conclusión, este trabajo muestra que en las personas que hemos definido como saludables existe una reingeniería corporal que les permite llevar satisfactoriamente una vida armónica con su ambiente y que en nuestra sociedad ocurre en forma diferenciada para el hombre y para la mujer, probablemente por efectos dietéticos nutricionales y actividades sociales físicas y laborales en el concepto de mantener una imagen corporal estable y satisfactoria a través de la vida.

\section{Declaración de financiamiento y de conflictos de intereses:}

El estudio fue financiado por los autores. Declaran no tener conflictos de intereses.

\section{Declaración de autoría:}

ARVS, JACZ: Participaron en el diseño del estudio, recolección de los datos, interpretación de los resultados y aprobación de la versión final a ser publicada.

\section{Correspondencia:}

Ana Rosa Vilela Sangay

Correo electrónico: ana.vilela@upch.pe 


\section{REFERENCIAS BIBLIOGRÁFICAS}

1. Organización Mundial de la salud. Constitución de la Organización Mundial de la Salud. Ginebra: Organización Mundial de la salud;1948. (Fecha de acceso 10 de setiembre del 2018) Disponible en: http://www.who.int/about/mission/es/

2. Guyton A, Hall J. Organización funcional del cuerpo humano. En: Guyton A, Hall J. Tratado de fisiología médica. 12th ed. Barcelona: Elsevier; 2011. pp. 3-9.

3. Pereira da Silva A, Matos A, Valente A, et al. Body composition assessment and nutritional status evaluation in men and women portuguese centenarians. J Nutr Health Aging. 2016; 20(3):25666.

4. Chumlea WC, Guo SS, Zeller CM, Reo NV, Siervogel RM. Total body water data for white adults 18 to 64 years of age: the Fels Longitudinal Study.Kidney Int. 1999 Jul; 56(1):244-52.

5. Kyle UG, Genton L, Hans D, Karsegard L, Slosman DO, Pichard C. Age-related differences in fatfree mass, skeletal muscle, body cell mass and fat mass between 18 and 94 years. Eur J Clin Nutr. 2001; 55(8):663-72.

6. Powles J, Fahimi S, Micha R, et al. Global, regional and national sodium intakes in 1990 and 2010: A systematic analysis of $24 \mathrm{~h}$ urinary sodium excretion and dietary surveys worldwide. BMJ Open. 2013; $3: 1-19$.
7. Lamelas PM, Mente A, Diaz R, et al. Association of urinary sodium excretion with blood pressure and cardiovascular clinical events in 17,033 Latin Americans. Am J Hypertens. 2016; 29(7):796-805.

8. Carrillo-Larco RM, Saavedra-Garcia L, Miranda JJ, et al. Sodium and potassium consumption in a semiurban area in Peru: evaluation of a population-based 24-Hour urine collection. Nutrients. 2018; 10(2):245.

9. Cieza J, Rosas M. Prevalencia de hipertensión arterial, diabetes mellitus tipo 2, enfermedad renal crónica y obesidad en una población urbana de los distritos de Carabayllo, Comas e Independencia en los años 2014 y 2015. Acta Médica Peruana. 2016; 33(4):296-303.

10. World Health Organization. Guideline: sodium intake for adults and children. World Health Organization. Geneva: World Health Organization; 2012?.

11. Espinoza SL. Determinación del consumo de sal corriente y sodio en estudiantes universitarios de la facultad de medicina. Tesis para optar el grado de Maestría. Lima, Perú: Universidad Nacional Mayor de San Marcos; 2016.

12. Alegria-Lertxundi I, Rocandio A, Telletxea S, Rincón E, Arroyo-Izaga M.Relación entre el índice de consumo de pescado y carne y la adecuación y calidad de la dieta en mujeres jóvenes universitarias. Nutr Hosp. 2014; 30(5):1135-1143.

Recibido: 26/07/2018

Aceptado: 26/09/2018 